\title{
A Randomized, Double-Blind, Placebo-Controlled Trial of Vilazodone in Children and Adolescents with Major Depressive Disorder with Twenty-Six-Week Open-Label Follow-Up
}

\author{
Robert L. Findling, MD, MBA, Emily McCusker, $\mathrm{PhD},{ }^{2}$ and Jeffrey R. Strawn, MD, FAACAP ${ }^{3,4}$
}

\begin{abstract}
Objective: To evaluate the efficacy and long-term safety of vilazodone in children and adolescent outpatients with major depressive disorder (MDD).

Methods: Children and adolescents aged 7-17 years of age with MDD were randomized 2:2:1 to 8 weeks of double-blind placebo, vilazodone 15 or $30 \mathrm{mg} /$ day or fluoxetine $20 \mathrm{mg} /$ day, respectively. The primary and secondary efficacy outcomes, respectively, were change from baseline to week 8 in Children's Depression Rating Scale-Revised (CDRS-R) score total score and Clinical Global Impressions-Severity (CGI-S) score analyzed using a mixed model for repeated measurement approach. Patients who completed the 8-week randomized controlled trial (RCT), as well as new (de novo) patients, could participate in a 26-week, vilazodone-only, open-label extension (OLE) study.

Results: The RCT enrolled 473 patients (60\% female) with an average age of 13 years. Change in CDRS-R and CGI-S scores from baseline to week 8 did not differ between patients who received vilazodone and those randomized to placebo. The leastsquares mean change from baseline in CDRS-R scores was similar for vilazodone and placebo ( -20.7 vs. $-20.3, p=0.77$; least-squares mean difference $[\mathrm{LSMD}]=-0.40)$. For fluoxetine, the LSMD versus placebo was $-2.3(p=0.14)$. The OLE enrolled 330 patients (60\% female) with an average age of 13-14 years. Overall, no new safety concerns were identified compared to what is known in adults.

Conclusions: Similar improvements in depressive symptoms were observed in all arms. This study does not support the efficacy of vilazodone 15 or $30 \mathrm{mg} /$ day for pediatric patients with MDD. No new or unexpected safety concerns were detected during the RCT or OLE studies.
\end{abstract}

Keywords: vilazodone, major depressive disorder, treatment efficacy, clinical trial, children, adolescents

\section{Introduction}

D EPRESSIVE DISORDERS ARE COMMON in children and adolescents with major depressive disorder (MDD) affecting more than 1 in 10 adolescents between the ages of 13 and 17 years (Merikangas et al. 2007; Kessler et al. 2012). When present during childhood or adolescence, MDD impairs academic performance and peer relationships and increases the risk of recurrent depression in adulthood (Davies et al. 2018). In addition, MDD represents a significant risk factor for suicidal ideation, suicide attempts, and completed suicides - the third leading cause of death in adolescents worldwide (Foley et al. 2006; Thapar et al. 2012; World Health Organization 2019). Despite the high prevalence and associated morbidity and mortality, pharmacological treatment options are limited for youth with MDD.

The current approach to treating children and adolescents with MDD includes psychotherapy (Mufson et al. 1999, 2004; The Treatment for Adolescents with Depression Study [TADS] 2009) in

\footnotetext{
${ }^{1}$ Department of Psychiatry, Virginia Commonwealth University, Richmond, Virginia, USA.

${ }^{2} \mathrm{CNS}$, AbbVie, Irvine, California, USA.

${ }^{3}$ Anxiety Disorders Research Program, University of Cincinnati, Cincinnati, Ohio, USA.

${ }^{4}$ Department of Psychiatry \& Behavioral Neuroscience, Cincinnati Children's Hospital Medical Center, Cincinnati, Ohio, USA.

Funding: These studies and data analysis were supported by funding from Allergan plc (now AbbVie).
}

(c) Robert L. Findling et al. 2020; Published by Mary Ann Liebert, Inc. This Open Access article is distributed under the terms of the Creative Commons Attribution Noncommercial License (http://creativecommons.org/licenses/by-nc/4.0/) which permits any noncommercial use, distribution, and reproduction in any medium, provided the original author(s) and the source are cited. 
addition to selective serotonin reuptake inhibitors (SSRIs) (Emslie et al. 2002, 2008, 2009; Wagner et al. 2003; The Treatment for Adolescents with Depression Study [TADS] 2009; Strawn et al. 2017). To date, only two medications have received approval from the U.S. Food and Drug Administration (FDA) for children and adolescents with MDD: fluoxetine (indicated for ages 8-17) and escitalopram (indicated for ages 12-17) (Emslie et al. 2002, 2009). However, as many as $40 \%$ of patients fail to adequately respond to SSRIs (The Treatment for Adolescents with Depression Study [TADS] 2009; Emslie et al. 2010). Given the significant burden associated with pediatric MDD and the limited effect of available medications, there is an urgent need to evaluate additional pharmacologic treatments with alternative mechanisms of action.

Vilazodone, an SSRI and 5-HT $\mathrm{HA}_{1 \mathrm{~A}}$ partial agonist, reduces depressive symptoms in adults and is approved for the treatment of MDD in adults (Croft et al. 2014; Viibryd ${ }^{\circledR} 2017$ ). To date, only one randomized controlled trial (RCT) has examined the efficacy and safety of fixed-dose vilazodone 15 or $30 \mathrm{mg}$ /day in adolescents with MDD (Durgam et al. 2018). Although the safety profile of vilazodone in that trial was similar to that observed in adults, this trial failed to identify significant differences in improvement in depressive symptoms between patients receiving placebo and those receiving vilazodone. Furthermore, this vilazodone study had a very high placebo response rate. Specifically, more than half of patients receiving placebo were rated as "very much" or "much improved" on the categorical response measure. A second RCT was conducted to evaluate the safety and efficacy of flexibly-dosed vilazodone in children and adolescents (aged 7-17 years) with $\mathrm{MDD}$, as well as its long-term safety in a follow-up open-label extension (OLE) study.

\section{Methods}

\section{Study design and patient selection}

The 8-week, multisite randomized, double-blind, placebocontrolled phase 3 trial compared flexibly-dosed vilazodone (15$30 \mathrm{mg} /$ day) to placebo in children and adolescents with MDD. The study was conducted from October 2014 to September 2018 at 55 centers in the United States and Canada (ClinicalTrials.gov: NCT02372799). The 26-week OLE was an open-label flexibledose study conducted at the same 55 centers from May 2015 to November 2018 (ClinicalTrials.gov: NCT02436239), which enrolled those patients completing the 8-week RCT, as well as new (de novo) patients. Both studies were approved by institutional review boards or independent ethics committees at each study center, and all patients (or a parent or legal guardian) provided written informed assent and consent. Both studies were conducted in accordance with the Declaration of Helsinki and International Conference on Harmonization Guidelines for Good Clinical Practice.

For both studies, eligible patients included children and adolescents aged 7-17 years with a diagnosis of MDD for $\geq 6$ weeks duration at Screening based on the Diagnostic and Statistical Manual of Mental Disorders, Fourth Edition, Text Revision (DSMIV-TR; American Psychiatric Association 2000) criteria and were confirmed by the Kiddie Schedule for Affective Disorders and Schizophrenia-Present and Lifetime interview (Kaufman et al. 1997). Inclusion criteria were a Children's Depression Rating Scale-Revised (CDRS-R) (Poznanski and Mokros 1996) total score $\geq 40$ and Clinical Global Impressions-Severity (CGI-S) (Guy 1976) score $\geq 4$ at baseline. Patients were required to have a caregiver responsible for safety monitoring, providing information about the patient's condition, overseeing the study drug administration, and accompanying the patient to study visits. Patients who turned 18 years old during the study were re-consented.

Exclusion criteria included a current (past 3 months) principal DSM-IV-TR Axis I diagnosis other than MDD within 6 months before screening. However, patients with comorbid learning disorders, attention deficit disorder (with or without hyperactivity), communication disorders, oppositional defiant disorder, and anxiety disorders were allowed to participate in the study as long as these were not the primary focus of treatment and complied with concomitant medications. A history of a suicide attempt within the past year or a current significant suicide risk as judged by the investigator based on interview or information collected in the Columbia-Suicide Severity Rating Scale (C-SSRS) was exclusionary (Posner et al. 2011). A more detailed listing of inclusion/ exclusion criteria and permitted psychotropic medications are listed in Supplementary Table S1.

\section{Eight-week $R C T$}

Treatment groups and blinding. The sponsor generated a list of patient randomized allocation codes corresponding to assigned investigational products (IPs) that was implemented by the interactive web response system vendor to maintain blinding. This list identified each patient by randomization number and included the patient's corresponding treatment assignment. Patients, investigators, and study staff were blinded to treatment assignments and study medication consisting of tablets or capsules (identical to placebo in size, shape, color, taste, and packaging). Blinding was maintained for the 8-week treatment and 1-week down-taper periods. Patients were randomized 2:2:1 to placebo, flexibly-dosed vilazodone $(15-30 \mathrm{mg} /$ day $)$, or fluoxetine $(20 \mathrm{mg} /$ day $)$. Of note, fluoxetine was included as an active comparator/reference treatment because it is approved for treating MDD in pediatric (children and adolescents) patients. The dosage selected in this study was based on the FDA approved dosage in this patient population, which was assessed in two pivotal trials, of 10-20 mg/day (PRO$\mathrm{ZAC}^{\circledR}$ 2014).

IPs in the form of tablets and capsules were provided by the sponsor packaged in blister cards labeled with blinded allocation codes. Patients were supplied with IP and were instructed to take three tablets and one capsule orally, once-daily as a single dose (morning dosing was recommended). Fluoxetine was encapsulated to protect the blind. Throughout the study, it was recommended that patients take the IP at the same time each day with food. Vilazodone was titrated to $15 \mathrm{mg}$ /day in two steps by the end of week 2 and could be increased to $30 \mathrm{mg} /$ day no later than the start of week 3 based on improvement and tolerability (Supplementary Fig. S1). Fluoxetine was titrated to $20 \mathrm{mg} /$ day by the end of week 2 . A single reduction to $15 \mathrm{mg}$ /day was allowed for tolerability in patients taking vilazodone $30 \mathrm{mg} / \mathrm{day}$. After the treatment period, during the 1-week down-taper period, vilazodone 15 and $30 \mathrm{mg} /$ day was reduced to $5 \mathrm{mg} /$ day in one step and two steps, respectively. Fluoxetine was reduced to $10 \mathrm{mg} /$ day.

Prespecified efficacy and safety assessments. The primary efficacy endpoint was change from baseline to week 8 in CDRS-R total score (Poznanski and Mokros 1996). The secondary efficacy endpoint was change from baseline to week 8 in CGI-S score (Guy 1976). The primary and secondary efficacy endpoints were the same as those used in the previously published vilazodone for adolescent patients for MDD study (Durgam et al. 2018). 
CDRS-R total score and CGI-S score assessments were conducted at screening, baseline, and all subsequent study visits. Additional efficacy assessments included Clinical Global ImpressionsImprovement (CGI-I) score and the CDRS-R response [ $\geq 40 \%$ reduction from baseline in CDRS-R total score (Emslie et al. 2002)] and CDRS-R remission (total score $\leq 28$ ) rates. Safety measures included adverse events (AEs), laboratory parameters, vital signs, electrocardiogram (EKG) parameters, and suicidality.

Statistical analyses. Based on a mixed-effects model for repeated measures (MMRM) model using simulation data, a sample size of 400 patients (160 per group for placebo and vilazodone) was planned to provide $85 \%$ power to detect an effect size of 0.36 for the primary efficacy measure (treatment group difference of $4 \mathrm{U}$ relative to pooled standard deviation [SD] of 11.1) ( $\mathrm{Lu} \mathrm{2012).} \mathrm{The} \mathrm{simulation} \mathrm{assumed} \mathrm{a} \mathrm{correlation} \mathrm{of} 0.7$ between repeated measures and a dropout rate of $17 \%$ based on historical studies in children and adolescents with MDD (Emslie et al. 2009). A planned blinded interim analysis was conducted after obtaining $75 \%$ of planned sample and resulted in an increase in the planned sample size to 455 patients (based on a pooled SD of 12.3). A second interim analysis was conducted after 400 patients were enrolled, and it was determined that a sample size of 470 patients (188 per group for placebo and vilazodone and 94 for fluoxetine) was required to maintain the $85 \%$ statistical power to detect a treatment difference of $4 \mathrm{U}$ for the CDRS-R.

Change in CDRS-R scores was examined using MMRM with treatment group, pooled study center, visit, and treatment group-byvisit interaction as fixed effects and the baseline score and baseline score-by-visit interaction as the covariates. The covariance of withinpatient scores was modeled with an unstructured covariance matrix, and denominator degrees of freedom were estimated using the Kenward-Roger approximation (Kenward and Roger 1997). Analysis was based on all postbaseline scores using only the observed cases (OC) and without imputation of missing values for the intent-to-treat (ITT) population, defined as patients who had at least one postbaseline CDRS-R score.

CGI-S scores were also examined using MMRM with baseline CGI-S score and baseline CGI-S score-by-visit interaction used as covariates. The overall family-wise type I error rate for testing CDRS$\mathrm{R}$ and CGI-S scores was controlled at the 0.05 significance level using the fixed sequence testing procedure. The statistical analysis of CGI-S was tested only if the primary analysis met statistical significance. CGI-I was analyzed using MMRM (similar to the analysis of CDRS$\mathrm{R}$ scores) with CGI-I score used as a covariate.

Response $(\geq 40 \%$ reduction in CDRS-R raw total score from baseline) and remission (CDRS-R score $\leq 28$ ) rates were examined using generalized linear mixed models, based on logit link function, with random intercept and fixed terms of treatment group, visit, treatment-by-visit interaction, and baseline score. Safety analyses were performed for the double-blind treatment period and the double-blind down-taper period separately in the safety population defined as all randomized patients who took at least one dose of double-blind study medication (or placebo).

\section{Twenty-six week OLE}

While all participants in the OLE received vilazodone, treatment groups were designated based on the participant's RCT treatment group (placebo, vilazodone, or fluoxetine). Patients rolling over from the down-taper period of the RCT comprised the "lead-in" treatment group and were not required to undergo a washout period; however, de novo patients completed a 1-week (minimum) screening/prohibited medication washout period. Similar to the RCT study design, vilazodone was titrated up to $15 \mathrm{mg} /$ day by the end of week 2 of the OLE with the option to increase to $30 \mathrm{mg} /$ day at the beginning of week 3 , culminating with a 1 -week down-taper period at the end of the 26 weeks (Supplementary Fig. S1). Vilazodone was supplied as tablets and instructed to be taken once daily as a single dose at the same time each day with food.

Efficacy and safety assessments. The efficacy assessment analyses were based on the ITT Population and included the change from baseline in CDRS-R total score, CGI-S score, and CGI-I score. Safety assessments included AEs, laboratory parameters, vital sign measurements, electrocardiogram (ECG) parameters, and suicidality using C-SSRS assessments.

Raters. Each site had a qualified rater perform CDRS-R and CGI-I assessments. Each rater had a minimum of 2 years experience and scale use (more than 10 times and 5 times in the previous 12 months for CGI-I and CDRS-S, respectively); all raters were requalified annually.

Statistical analyses. Descriptive statistics for efficacy parameters was summarized for each visit, by treatment group for continuous variables using the $\mathrm{OC}$ approach. For de novo patients, the latest nonmissing evaluation of efficacy variables before the first dose of OLE vilazodone was used as baseline. Baseline efficacy parameters from the RCT study were used for lead-in treatment groups. Safety analyses were performed on the Safety Population, defined as above. For lead-in treatment groups, an AE was considered a treatment-emergent adverse event (TEAE) if it was not present before the first dose of study medication (or placebo) in the RCT or if present before the first dose of RCT study medication (or placebo) with increased severity during the OLE. For de novo patients, the latest nonmissing evaluation of safety variables before the first dose of OLE vilazodone was used as baseline. Baseline safety assessment of laboratories, vitals, body weight, growth, and ECGs from the RCT study was used for lead-in treatment groups.

\section{Results}

A total of 473 patients were randomized, and 470 were included in the double-blind safety population ( $n=186$ placebo, $n=187$ vilazodone $15-30 \mathrm{mg} / \mathrm{day}$, and $n=97$ fluoxetine $20 \mathrm{mg} / \mathrm{day}$ in the 8 week RCT) (Fig. 1). Demographic and clinical characteristics were similar across treatment groups (Table 1). Psychiatric history characteristics were generally similar among treatment groups with a mean number of MDD episodes $\sim 1.3$ and mean duration of MDD of $\sim 2$ years (Table 2). Baseline CDRS-R total scores were comparable among treatment groups (57.3-58.3). Baseline CGI-S scores were also comparable across groups (4.6-4.7) and indicative of a population with moderate-to-marked illness severity on average. Overall, $389(82.8 \%)$ patients completed the double-blind treatment period $(81.7 \%$ placebo, $82.9 \%$ vilazodone, and $84.5 \%$ fluoxetine) (Fig. 1). The most frequent reasons for premature discontinuation were: withdrawal of consent (4.7\%), AEs (4.0\%), and lost to follow-up (4.0\%). Discontinuation due to AEs was higher in patients treated with fluoxetine $(6.2 \%)$ and vilazodone $(4.8 \%)$ compared to placebo $(1.6 \%)$ patients.

A total of 318 patients rolling over from the RCT made up the "lead-in" population, and 12 de novo patients were enrolled for a 


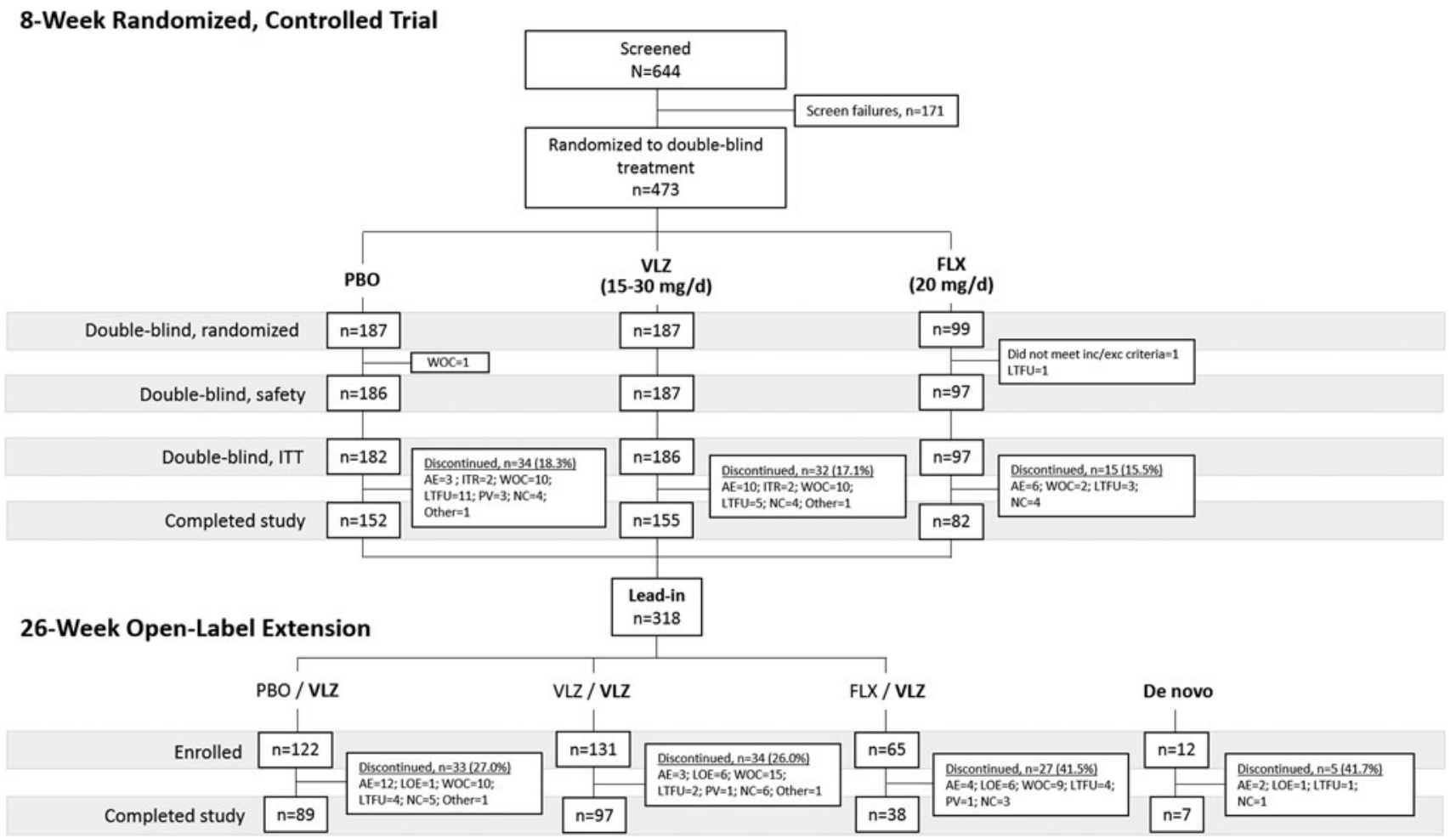

FIG. 1. Study flow and patient disposition. $N$, number of screened patients; $n$, number of patients within a specific category; PBO, placebo; VLZ, vilazodone; FLX, fluoxetine; WOC, withdrawal of consent; ITT, intent-to-treat; AE, adverse event; ITR, insufficient therapeutic response; LTFU, lost to follow-up; PV, protocol violation; NC, noncompliance; LOE, lack of efficacy.

Table 1. Baseline Demographics, by Study and Treatment Group (Safety Population)

\begin{tabular}{|c|c|c|c|c|c|c|c|c|}
\hline \multirow[b]{3}{*}{ Statistic or characteristic } & \multicolumn{3}{|c|}{ Randomized controlled trial } & \multicolumn{5}{|c|}{ Open-label extension } \\
\hline & \multirow[b]{2}{*}{$\begin{array}{c}P B O \\
\mathrm{~N}=186\end{array}$} & \multirow[b]{2}{*}{$\begin{array}{c}V L Z \\
\mathrm{~N}=187\end{array}$} & \multirow[b]{2}{*}{$\begin{array}{c}F L X \\
\mathrm{~N}=97\end{array}$} & \multicolumn{3}{|c|}{ Lead-in treatment group } & \multirow{2}{*}{$\begin{array}{l}\text { Total } \\
\text { Lead-in } \\
\mathrm{N}=318\end{array}$} & \multirow{2}{*}{$\begin{array}{c}\text { Total } \\
\text { De novo } \\
\mathrm{N}=12\end{array}$} \\
\hline & & & & $\begin{array}{c}P B O / V L Z \\
\mathrm{~N}=122\end{array}$ & $\begin{array}{c}V L Z / V L Z \\
\mathrm{~N}=131\end{array}$ & $\begin{array}{c}F L X / V L Z \\
\mathrm{~N}=65\end{array}$ & & \\
\hline \multicolumn{9}{|l|}{ Age, years } \\
\hline Mean (SD) & $13.0(2.9)$ & $13.0(2.9)$ & $13.2(2.8)$ & $13.0(2.9)$ & $13.3(2.8)$ & $13.2(2.8)$ & $13.3(2.8)$ & $13.0(3.6)$ \\
\hline Median (min, max) & $13.5(7,17)$ & $13.0(7,17)$ & $14.0(7,17)$ & $14.0(7,17)$ & $14.0(7,18)$ & $14.0(7,17)$ & $14.0(7,18)$ & $13.5(7,17)$ \\
\hline \multicolumn{9}{|l|}{ Sex, $n(\%)$} \\
\hline Male & $80(43.0)$ & $61(32.6)$ & $46(47.4)$ & $54(44.3)$ & $42(32.1)$ & $32(49.2)$ & $128(40.3)$ & $5(41.7)$ \\
\hline Female & $106(57.0)$ & $126(67.4)$ & $51(52.6)$ & $68(55.7)$ & $89(67.9)$ & $33(50.8)$ & $190(59.7)$ & $7(58.3)$ \\
\hline \multicolumn{9}{|l|}{ Mean weight, kg (SD) } \\
\hline Mean BMI, kg/m² (SD) & $59.1(24.3)$ & $61.3(24.8)$ & $59.4(21.1)$ & $57.9(23.5)$ & $62.7(25.3)$ & $59.4(18.9)$ & $60.2(23.5)$ & $60.3(17.9)$ \\
\hline & $23.3(6.8)$ & $24.2(7.6)$ & $23.5(6.7)$ & $22.7(6.6)$ & $24.7(8.0)$ & $23.3(5.4)$ & $23.7(7.0)$ & $23.9(6.2)$ \\
\hline \multicolumn{9}{|l|}{ Race, $n(\%)$} \\
\hline White & $118(63.4)$ & $121(64.7)$ & $60(61.9)$ & $82(67.2)$ & $84(64.1)$ & $42(64.6)$ & $208(65.4)$ & $11(91.7)$ \\
\hline All other races & $68(36.6)$ & $66(35.3)$ & $36(37.1)$ & $40(32.8)$ & $47(35.9)$ & $23(35.4)$ & $110(34.6)$ & $1(8.3)$ \\
\hline Black/African American & $57(30.6)$ & $58(31.0)$ & $30(30.9)$ & $32(26.2)$ & $40(30.5)$ & $20(30.8)$ & $92(28.9)$ & $1(8.3)$ \\
\hline Asian & $5(2.7)$ & $1(0.5)$ & $1(1.0)$ & $5(4.1)$ & $1(0.8)$ & $1(1.5)$ & $7(2.2)$ & 0 \\
\hline $\begin{array}{l}\text { Native Hawaiian } \\
\text { or Other } \\
\text { Pacific Islander }\end{array}$ & $1(0.5)$ & $2(1.1)$ & 0 & 0 & $2(1.5)$ & 0 & $2(0.6)$ & 0 \\
\hline Other/multiple & $5(2.7)$ & $5(2.7)$ & $5(5.2)$ & $3(2.5)$ & $4(3.1)$ & $2(3.1)$ & $9(2.8)$ & 0 \\
\hline \multicolumn{9}{|l|}{ Ethnicity, $n(\%)$} \\
\hline Hispanic/Latino & $27(14.5)$ & $25(13.4)$ & $12(12.4)$ & $16(13.1)$ & $16(12.2)$ & $8(12.3)$ & $40(12.6)$ & $2(16.7)$ \\
\hline Not Hispanic/Latino & $159(85.5)$ & $162(86.6)$ & $85(87.6)$ & $106(86.9)$ & $115(87.8)$ & $57(87.7)$ & $278(87.4)$ & $10(83.3)$ \\
\hline Missing value & 0 & 0 & $1(1.0)$ & 0 & 0 & 0 & 0 & 0 \\
\hline
\end{tabular}

PBO, placebo; VLZ, vilazodone; FLX, fluoxetine; $N$, number of patients in the ITT population; $n$, number of patients within a specific category; SD, standard deviation; BMI, body mass index; ITT, intent-to-treat. 
Table 2. Psychiatric History of Major Depressive Disorder at Baseline, by Study and Treatment Group (Safety Population)

\begin{tabular}{|c|c|c|c|c|c|c|c|c|}
\hline \multirow[b]{2}{*}{ Statistic or characteristic } & \multicolumn{3}{|c|}{ Randomized controlled trail } & \multicolumn{5}{|c|}{ Open-label extension } \\
\hline & $\begin{array}{c}P B O \\
\mathrm{~N}=186\end{array}$ & $\begin{array}{c}V L Z \\
\mathrm{~N}=187\end{array}$ & $\begin{array}{c}F L X \\
\mathrm{~N}=97\end{array}$ & $\begin{array}{c}P B O / V L Z \\
\mathrm{~N}=122\end{array}$ & $\begin{array}{c}V L Z / V L Z \\
\mathrm{~N}=131\end{array}$ & $\begin{array}{c}F L X / V L Z \\
\mathrm{~N}=65\end{array}$ & $\begin{array}{l}\text { Lead-in } \\
\mathrm{N}=318\end{array}$ & $\begin{array}{c}\text { De novo } \\
\mathrm{N}=12\end{array}$ \\
\hline \multicolumn{9}{|l|}{ Major depression, $n(\%)$} \\
\hline Recurrent & $74(39.8)$ & $84(44.9)$ & $37(38.1)$ & $48(39.3)$ & $61(46.6)$ & $25(38.5)$ & $134(42.1)$ & 0 \\
\hline Single episodes & $112(60.2)$ & $103(55.1)$ & $60(61.9)$ & $74(60.7)$ & $70(53.4)$ & $40(61.5)$ & $184(57.9)$ & $12(100.0)$ \\
\hline Number of MDD episodes & & & & & & & & \\
\hline Mean (SD) & $1.7(1.3)$ & $1.8(1.2)$ & $1.8(1.6)$ & $1.7(1.4)$ & $1.8(1.3)$ & $1.9(1.9)$ & $1.8(1.5)$ & $1.0(0.0)$ \\
\hline Duration of MDD, years & & & & & & & & \\
\hline Mean (SD) & $2.1(2.1)$ & $2.3(2.1)$ & $2.2(2.3)$ & $2.1(2.2)$ & $2.3(2.1)$ & $1.9(1.7)$ & $2.1(2.1)$ & $2.2(1.8)$ \\
\hline Duration of current episod & e, months & & & & & & & \\
\hline Mean (SD) & $11.1(12.8)$ & $11.2(16.2)$ & $11.9(14.0)$ & $10.2(11.1)$ & $11.1(16.7)$ & $10.5(12.1)$ & $10.6(13.8)$ & $27.2(21.6)$ \\
\hline $\begin{array}{l}\text { Age at onset, years } \\
\text { Mean (SD) }\end{array}$ & $10.9(3.3)$ & $10.7(3.2)$ & $10.9(3.0)$ & $11.0(3.3)$ & $10.9(3.0)$ & $11.2(2.9)$ & $11.0(3.1)$ & $10.8(3.9)$ \\
\hline Attempted suicide, $n(\%)$ & & & & & & & & \\
\hline Yes & $8(4.3)$ & $5(2.7)$ & $2(2.1)$ & $1(0.8)$ & $3(2.3)$ & $2(3.1)$ & $6(1.9)$ & $2(16.7)$ \\
\hline No & $178(95.7)$ & $182(97.3)$ & 95 (97.9) & $121(99.2)$ & $128(97.7)$ & $63(96.9)$ & $312(98.1)$ & $10(83.3)$ \\
\hline $\begin{array}{l}\text { CDRS-R total score } \\
\text { Mean (SD) }\end{array}$ & $57.3(9.2)$ & $58.3(9.2)$ & $58.0(8.8)$ & $57.7(9.6)$ & $59.3(9.5)$ & $57.8(8.7)$ & $58.4(9.4)$ & $59.7(9.1)$ \\
\hline $\begin{array}{l}\text { CGI-S score } \\
\text { Mean (SD) }\end{array}$ & $4.6(0.6)$ & $4.7(0.6)$ & $4.6(0.6)$ & $4.6(0.6)$ & $4.7(0.7)$ & $4.6(0.6)$ & $4.7(0.6)$ & $4.2(0.4)$ \\
\hline
\end{tabular}

PBO, placebo; VLZ, vilazodone; FLX, fluoxetine; $N$, number of patients in the safety population; $n$, number of patients within a specific category; SD, standard deviation; MDD, major depressive disorder; CGI-S, Clinical Global Impressions-Severity; CDRS-R, Children's Depression Rating ScaleRevised.

total of 330 patients in the OLE Safety Population (Fig. 1). Patient demographics and baseline characteristics were comparable across groups and reflected those of the RCT population (Table 1); however, mean duration of current depressive episode was much longer in the de novo (27.2 months) compared to the lead-in group (10.6 months) (Table 2). Among the 231 (70.0\%) who completed the OLE, $97.0 \%$ were lead-in and $3.0 \%$ were de novo patients (Fig. 1).

\section{Extent of exposure}

In the RCT, the mean (SD) treatment duration among treatment groups was 50.3 (14.3) days for placebo, 50.8 (13.6) days for vilazodone $15-30 \mathrm{mg} / \mathrm{day}$, and 52.1 (12.3) days for fluoxetine $20 \mathrm{mg} /$ day. The mean daily dose of vilazodone was $19.9 \mathrm{mg} /$ day; the mean daily dose of fluoxetine was $17.5 \mathrm{mg} /$ day. In the OLE, the mean (SD) treatment duration among groups was 155.2 (52.3) days for placebo/vilazodone (pbo/vlz), 154.0 (53.6) days for vilazodone/vilazodone (vlz/vlz), 135.5 (64.3) days for fluoxetine/vilazodone (flx/vlz), and 121.5 (76.8) days for de novo. The mean daily dose of vilazodone across groups was $20.2 \mathrm{mg} /$ day in the OLE.

\section{Efficacy}

In the 8-week RCT, the MMRM analysis of the CDRS-R total score change from baseline to week 8 (primary endpoint) was not significant, with a least-squares mean difference (LSMD) between vilazodone and placebo of -0.4 (95\% confidence inter$\mathrm{val}=-3.1,2.3 ; p=0.77$ ) (Table 3$)$, and significant separation from placebo was not observed at any timepoint before week 8 (Fig. 2). For fluoxetine, the LSMD versus placebo was $-2.3(p=0.14)$. In addition, vilazodone did not significantly improve the secondary
(CGI-S score) or additional outcomes (CDRS-R response/remission rates) assessed (Table 3), although CDRS-R response rates were numerically higher for the vilazodone group (51.3\%) compared to the placebo group $(43.2 \%)$.

In the 26-week OLE follow-up, lead-in and de novo patients improved with regard to depressive symptoms (CDRS-R total score) at week 4 and maintained improvement through week 26. (Fig. 3). At week 26, mean (SD) change from baseline in CDRS-R total score was numerically greater in lead-in patients compared with de novo, -29.6 (12.6) versus -24.5 (10.3), respectively (Table 4). This may partly result from using the RCT baseline value (and eight additional weeks of observation) for calculating changes during the OLE in the lead-in group, but the small number of patients in the de novo group limits the value of any comparison between the groups. A similar pattern occurred with CGI-S scores, with mean (SD) change of -2.5 (1.3) for the lead-in group compared to -1.7 (1.2) for the de novo group. Based on the CGI-I, an improvement in MDD was observed for all treatment groups at endpoint, with an overall mean (SD) CGI-I score of 2.1 (1.2) using the OC approach. There were no meaningful differences between any of the treatment groups in mean CGI-I at any visit.

\section{Adverse events}

In the RCT, a greater proportion of patients experienced a TEAE in the double-blind period in the vilazodone group (67.4\%) than the placebo $(50.0 \%)$ and fluoxetine $(49.5 \%)$ groups (Table 5). No deaths occurred. Seven serious AEs (SAEs) were reported in six patients: one placebo (croup infection), no vilazodone, and six fluoxetine (depressive symptom, auditory hallucination, and overdose in one patient each and suicidal ideation in three patients). 
Table 3. Change from Baseline to Week 8 in Children's Depression Rating Scale-Revised Total Score,

Clinical Global Impressions-Severity Score, Clinical Global Impressions-Improvement Score, Children's

Depression Rating Scale-Revised Response/Remission Rates in the Randomized Controlled Trial

(Mixed-Effects Model for Repeated Measures, Intent-to-Treat Population)

\begin{tabular}{|c|c|c|c|}
\hline Statistic $^{\mathrm{a}}$ or characteristic & $P B O \mathrm{~N}=182$ & $V L Z \mathrm{~N}=186$ & $F L X \mathrm{~N}=97$ \\
\hline \multicolumn{4}{|l|}{ Primary efficacy assessment } \\
\hline \multicolumn{4}{|l|}{ CDRS-R total score ${ }^{\mathrm{b}}$} \\
\hline Baseline, mean (SD) & $57.7(9.2)$ & $58.5(9.4)$ & $58.1(8.3)$ \\
\hline Week 8 , mean $\pm \mathrm{SD}$ & $37.8(13.7)$ & $37.2(14.2)$ & $34.7(12.8)$ \\
\hline Change at week 8, LS mean (SE) & $-20.3(1.0)$ & $-20.7(1.0)$ & $-22.71(1.3)$ \\
\hline LSMD vs. placebo $(95 \% \mathrm{CI})^{\mathrm{a}}$ & - & $-0.4(-3.1$ to 2.3$)$ & $-2.4(-5.6$ to 0.8$)$ \\
\hline$p$-Value ${ }^{\mathrm{a}}$ & - & 0.77 & 0.14 \\
\hline \multicolumn{4}{|l|}{ Secondary efficacy assessment } \\
\hline \multicolumn{4}{|l|}{ CGI-S total score ${ }^{\mathrm{c}}$} \\
\hline Baseline, mean (SD) & $4.6(0.6)$ & $4.7(0.6)$ & $4.6(0.6)$ \\
\hline Week 8 , mean (SD) & $3.1(1.3)$ & $3.1(1.3)$ & $2.8(1.2)$ \\
\hline Change at week 8, LS mean (SE) & $-1.5(0.1)$ & $-1.6(0.1)$ & $-1.7(0.1)$ \\
\hline LSMD vs. placebo $(95 \% \mathrm{CI})^{\mathrm{a}}$ & - & $-0.04(-0.3$ to 0.2$)$ & $-0.2(-0.5$ to 0.1$)$ \\
\hline$p$-Value ${ }^{\mathrm{a}}$ & - & 0.74 & 0.22 \\
\hline \multicolumn{4}{|l|}{ Additional efficacy assessments } \\
\hline \multicolumn{4}{|l|}{ CGI-I score } \\
\hline Week 8, LS mean (SE) & $2.5(0.1)$ & $2.5(0.1)$ & $2.4(0.1)$ \\
\hline$p$-Value ${ }^{\mathrm{b}}$ & - & 0.7058 & 0.5185 \\
\hline \multicolumn{4}{|c|}{ CDRS-R response rate (total score $\geq 40 \%$ reduction from baseline) } \\
\hline Responder, $n / N 1(\%)$ & $67 / 155(43.2)$ & $81 / 158(51.3)$ & $46 / 84(54.8)$ \\
\hline Odds ratio $(95 \% \mathrm{CI})^{\mathrm{c}}$ & - & $1.563(0.8-3.1)$ & $1.812(0.8-4.0)$ \\
\hline$p$-Value & - & 0.19 & 0.15 \\
\hline \multicolumn{4}{|l|}{ CDRS-R remission rate (Total score $\leq 28$ ) } \\
\hline Remitter, $n / N 1(\%)$ & $53 / 155(34.2)$ & $46 / 158(29.1)$ & $34 / 84(40.5)$ \\
\hline Odds ratio $(95 \% \mathrm{CI})^{\mathrm{c}}$ & - & $0.8(0.4-1.6)$ & $1.529(0.7-3.4)$ \\
\hline$p$-Value ${ }^{c}$ & - & 0.57 & 0.30 \\
\hline
\end{tabular}

${ }^{a}$ The estimates and $p$-values were obtained from an MMRM based on the observed cases with treatment group, pooled study center, visit, and treatment group by visit interaction as fixed effects and baseline and baseline-by-visit as covariates using an unstructured covariance matrix.

${ }^{\mathrm{b}}$ For comparisons with placebo, the estimates and $p$-values were obtained from an MMRM based on the observed cases with treatment group, pooled study center, visit, and treatment group-by-visit interaction as fixed effects and baseline CGI-S and baseline CGI-S-by-visit interaction as the covariates.

${ }^{c}$ Analyses were based on the observed cases using a generalized linear mixed model with logit link function, random intercept, and fixed terms of treatment group, visit, treatment group-by-visit interaction, and baseline score.

PBO, placebo; VLZ, vilazodone; FLX, fluoxetine; CGI-S, Clinical Global Impressions-Severity; CGI-I, Clinical Global Impressions-Improvement; CDRS-R, Children's Depression Rating Scale-Revised; $N$, number of patients in the ITT population; $N 1$, number of patients in the ITT population with CDRS-R scores at week 8; $n$, number of patients within a specific category; SD, standard deviation; SE, standard error; LS, least squares; LSMD, leastsquares mean difference; CI, confidence interval; MMRM, mixed-effects model for repeated measures; ITT, intent-to-treat.

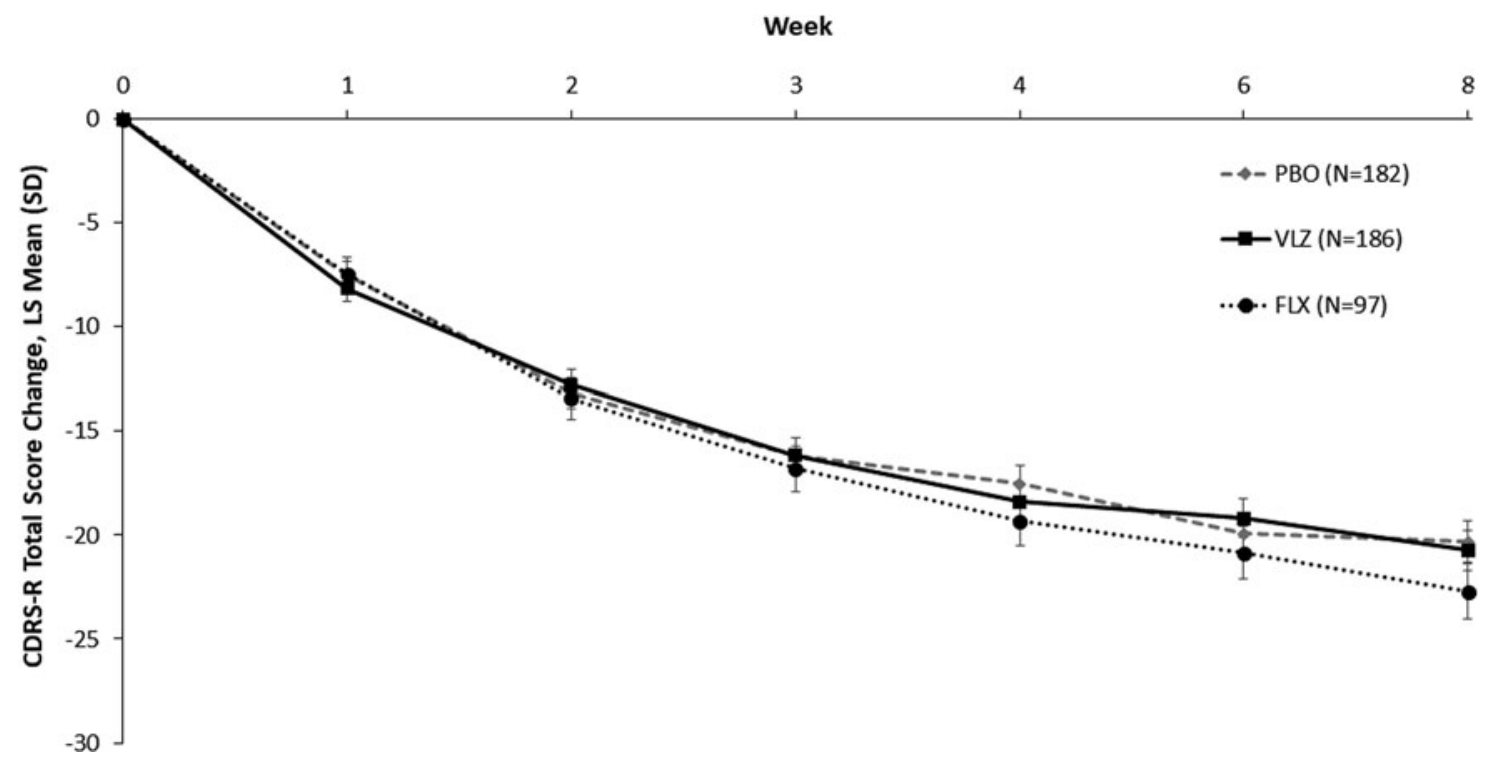

FIG. 2. Change from baseline in CDRS-R total score in the randomized controlled trial (MMRM, ITT population). CDRS-R, Children's Depression Rating Scale-Revised; MMRM, mixed-effects model for repeated measures; ITT, intent-to-treat; LS mean, least squares mean; SD, standard deviation; PBO, placebo; VLZ, vilazodone; FLX, fluoxetine. 


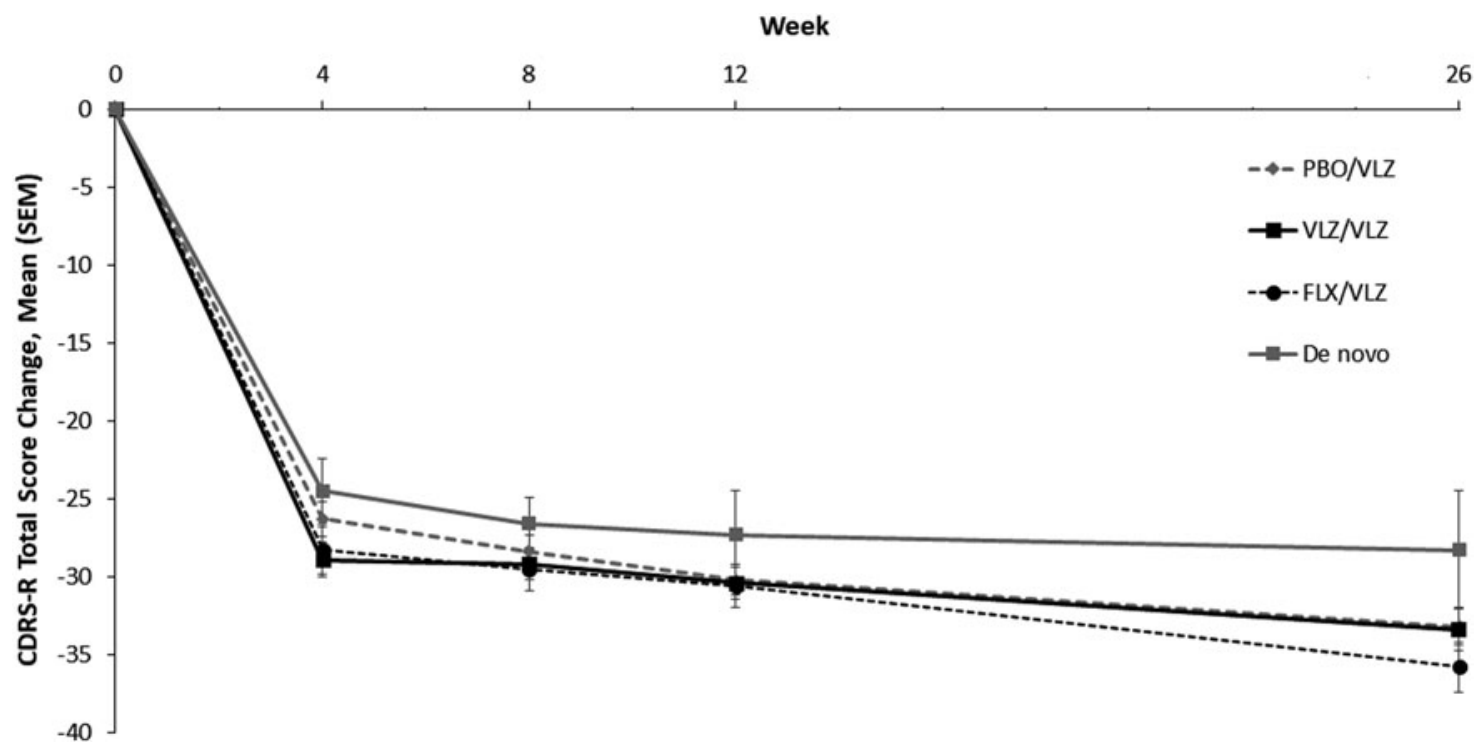

FIG. 3. Change from baseline in CDRS-R total score-by-visit in the open-label extension study (MMRM, ITT population). CDRS-R, Children's Depression Rating Scale-Revised; MMRM, mixed-effects model for repeated measures; ITT, intent-to-treat; LS mean, leastsquares mean; PBO, placebo; VLZ, vilazodone; FLX, fluoxetine.

Three placebo patients, nine vilazodone patients, and six fluoxetine patients had AEs that led to study discontinuation. AEs that led to discontinuation in more than one patient were diarrhea (two vilazodone patients), vomiting (two vilazodone patients), and suicidal ideation (three fluoxetine patients). TEAEs, which occurred in $\geq 5 \%$ of vilazodone patients and at a rate twice that of placebo, were nausea, vomiting, diarrhea, abdominal pain (upper), somnolence, and insomnia.

The incidence of common ( $\geq 2 \%$ and $\geq 2$ patients in any treatment group) TEAEs in the OLE is reported in Table 5. The overall incidence of TEAEs reported was lower in the total lead-in group than in the de novo group $(71.8 \%$ and $83.3 \%$ of patients, respectively). One 13-year-old male patient in the lead-in flx/vlz group died during the OLE study (accidental gunshot wound to the head, while cleaning firearm), which was determined to be unrelated to the study medication by the investigator. Six SAEs were reported in six patients in the pbo/vlz lead-in group, two of which were suicidal ideation and one event each of abnormal behavior, aggression, appendicitis, and suicide attempt. Of those SAEs, one suicidal ideation event was considered related to treatment. The three patients with SAEs related to suicidality were discontinued from the study.

\section{Suicidality}

In the RCT, the incidence of suicidal ideation, as assessed by an answer of "yes" to either question one or two of the Suicidal Ideation section of the C-SSRS, was similar in the fluoxetine and placebo groups and was lower in the vilazodone group $(13.4 \%$ placebo, $8.0 \%$ vilazodone, and $14.4 \%$ fluoxetine). Suicidal behavior was similar and low across the groups (one [0.5\%] patient each in the placebo and vilazodone groups and two [2.1\%] patients in the fluoxetine group). In the OLE, the incidences of suicidal ideation assessed by the C-SSRS were $11.6 \%$ in the total lead-in group $(13.1 \% \mathrm{pbo} / \mathrm{vlz}$ patients, $12.2 \% \mathrm{vlz} / \mathrm{vlz}$ patients, and $7.7 \%$ flx/vlz patients) and $33.3 \%$ in de novo patients. Suicidal behavior during the OLE was low across all groups ( $<2 \%$ of patients overall).

\section{Laboratory tests, vital signs, and ECGs}

In both the RCT and OLE study, the mean changes from baseline and the incidences of postbaseline potentially clinically significant changes in laboratory parameters and vital signs were similar among treatment groups. No patient met Hy's law criteria (Temple 2006); no new safety concerns were identified. No patient had a corrected QT interval by Bazett or corrected QT interval by

Table 4. Change from Baseline in Children's Depression Rating Scale-Revised Total Score and Clinical Global Impressions-Severity Score in the Open-Label Extension (Mixed-Effects Model for repeated Measures, Intent-to-Treat Population)

\begin{tabular}{|c|c|c|c|c|c|}
\hline \multirow[b]{2}{*}{ Statistic } & \multicolumn{3}{|c|}{ Lead-in treatment group } & \multirow[b]{2}{*}{ Total Lead-in $\mathrm{N}=314$} & \multirow[b]{2}{*}{ Total De novo $\mathrm{N}=11$} \\
\hline & $P B O / V L Z \mathrm{~N}=121$ & $V L Z / V L Z \mathrm{~N}=130$ & $F L X / V L Z \mathrm{~N}=63$ & & \\
\hline \multicolumn{6}{|c|}{ CDRS-R total score at end of treatment period } \\
\hline Mean (SD) & $28.5(11.9)$ & $29.2(12.2)$ & $28.4(12.2)$ & $28.8(12.0)$ & $35.2(12.5)$ \\
\hline Mean change (SD) & $-29.2(12.5)$ & $-30.1(12.2)$ & $-28.4(12.2)$ & $-29.6(12.6)$ & $-24.5(10.3)$ \\
\hline \multicolumn{6}{|c|}{ CGI-S score at end of treatment period } \\
\hline Mean (SD) & $2.1(1.2)$ & $2.1(1.3)$ & $2.0(1.2)$ & $2.1(1.3)$ & $2.5(1.3)$ \\
\hline Mean change (SD) & $-2.5(1.3)$ & $-2.6(1.4)$ & $-2.5(1.4)$ & $-2.5(1.3)$ & $-1.7(1.2)$ \\
\hline
\end{tabular}

PBO, placebo; VLZ, vilazodone; FLX, fluoxetine; CGI-S, Clinical Global Impressions-Severity; CDRS-R, Children's Depression Rating ScaleRevised; $N$, number of patients in the ITT population; SD, standard deviation; MMRM, mixed-effects model for repeated measures; ITT, intent-to-treat. 
Table 5. Summary of Adverse Events and Common Treatment-Emergent Adverse Events During Treatment Period, by Study and Treatment Group (Safety Population)

\begin{tabular}{|c|c|c|c|c|c|c|c|c|}
\hline \multirow[b]{3}{*}{ Statistic or characteristic, n, $\%$} & \multicolumn{3}{|c|}{ Randomized controlled trial } & \multicolumn{5}{|c|}{ Open-label extension study } \\
\hline & \multirow[b]{2}{*}{$\begin{array}{c}P B O \\
\mathrm{~N}=186\end{array}$} & \multirow[b]{2}{*}{$\begin{array}{c}V L Z \\
\mathrm{~N}=187\end{array}$} & \multirow[b]{2}{*}{$\begin{array}{c}F L X \\
\mathrm{~N}=97\end{array}$} & \multicolumn{3}{|c|}{ Lead-in treatment group } & \multirow[b]{2}{*}{$\begin{array}{c}\text { De novo } \\
\mathrm{N}=12\end{array}$} & \multirow[b]{2}{*}{$\begin{array}{c}\text { Total } \\
\mathrm{N}=330\end{array}$} \\
\hline & & & & $\begin{array}{l}P B O / V L Z \\
\mathrm{~N}=122\end{array}$ & $\begin{array}{l}V L Z / V L Z \\
\mathrm{~N}=131\end{array}$ & $\begin{array}{l}F L X / V L Z \\
\mathrm{~N}=65\end{array}$ & & \\
\hline \multicolumn{9}{|c|}{ AEs reported during treatment period } \\
\hline TEAE & $93(50.0)$ & $126(67.4)$ & $48(49.5)$ & $90(73.8)$ & 89 (67.9) & $48(73.8)$ & $10(83.3)$ & $237(71.8)$ \\
\hline SAE & $1(0.5)$ & 0 & $5(5.2)$ & $6(4.9)$ & 0 & $1(1.5)$ & 0 & $7(2.1)$ \\
\hline Deaths & 0 & 0 & 0 & 0 & 0 & $1(1.5)$ & 0 & $1(0.3)$ \\
\hline ADO & $3(1.6)$ & $9(4.8)$ & $6(6.2)$ & $12(9.8)$ & $3(2.3)$ & $3(4.6)$ & $2(16.7)$ & $20(6.1)$ \\
\hline \multirow{2}{*}{\multicolumn{9}{|c|}{$\begin{array}{l}\text { TEAEs reported in } \geq 5 \% \text { of patients in any treatment group } \\
\text { Preferred term, } n(\%)\end{array}$}} \\
\hline & & & & & & & & \\
\hline Nausea & $13(7.0)$ & $40(21.4)$ & $6(6.2)$ & $27(22.1)$ & $15(11.5)$ & $8(12.3)$ & $2(16.7)$ & $52(15.8)$ \\
\hline Headache & $31(16.7)$ & $24(12.8)$ & $10(10.3)$ & $20(16.4)$ & $28(21.4)$ & $8(12.3)$ & $2(16.7)$ & $58(17.6)$ \\
\hline Vomiting & $7(3.8)$ & $24(12.8)$ & $4(4.1)$ & $15(12.3)$ & $8(6.1)$ & $3(4.6)$ & 0 & $26(7.9)$ \\
\hline Diarrhea & $6(3.2)$ & $16(8.6)$ & $2(2.1)$ & $6(4.9)$ & $6(4.6)$ & $3(4.6)$ & 0 & $15(4.5)$ \\
\hline Abdominal pain, upper & $6(3.2)$ & $13(7.0)$ & $4(4.1)$ & $11(9.0)$ & $6(4.6)$ & $4(6.2)$ & 0 & $21(6.4)$ \\
\hline Somnolence & $4(2.2)$ & $12(6.4)$ & $2(2.1)$ & $4(3.3)$ & $4(3.1)$ & $2(3.1)$ & 0 & $10(3.0)$ \\
\hline Dizziness & $5(2.7)$ & $10(5.3)$ & $2(2.1)$ & $3(2.5)$ & $7(5.3)$ & $4(6.2)$ & 0 & $14(4.2)$ \\
\hline Insomnia & $3(1.6)$ & $10(5.3)$ & $6(6.2)$ & $12(9.8)$ & $11(8.4)$ & $2(3.1)$ & 0 & $25(7.6)$ \\
\hline URI & $5(2.7)$ & $6(3.2)$ & $5(5.2)$ & $11(9.0)$ & $10(7.6)$ & $6(9.2)$ & $4(33.3)$ & $31(9.4)$ \\
\hline Gastroenteritis & $2(1.1)$ & $4(2.1)$ & $1(1.0)$ & $6(4.9)$ & $3(2.3)$ & $3(4.6)$ & $1(8.3)$ & $13(3.9)$ \\
\hline Weight increased & 0 & $3(1.6)$ & $2(2.1)$ & $7(5.7)$ & $15(11.5)$ & $4(6.2)$ & $1(8.3)$ & $27(8.2)$ \\
\hline Nasopharyngitis & $5(2.7)$ & $3(1.6)$ & $4(4.1)$ & $5(4.1)$ & $10(7.6)$ & $2(3.1)$ & 0 & $17(5.2)$ \\
\hline Sinusitis & $2(1.1)$ & $2(1.1)$ & 0 & $1(0.8)$ & $5(3.8)$ & $2(3.1)$ & $1(8.3)$ & $9(2.7)$ \\
\hline Ear pain & 0 & $2(1.1)$ & 0 & 0 & $1(0.8)$ & 0 & $2(16.7)$ & $3(0.9)$ \\
\hline Dysmenorrhea & $2(1.1)$ & $1(0.5)$ & $1(1.0)$ & $3(4.4)$ & $4(4.5)$ & $3(9.1)$ & 0 & $10(5.1)$ \\
\hline Suicidal ideation & $2(1.1)$ & $1(0.5)$ & $5(5.2)$ & $3(2.5)$ & $5(3.8)$ & $1(1.5)$ & 0 & $9(2.7)$ \\
\hline Migraine & 0 & $1(0.5)$ & 0 & $3(2.5)$ & $3(2.3)$ & $1(1.5)$ & $1(8.3)$ & $8(2.4)$ \\
\hline Presyncope/syncope & 0 & $1(0.5)$ & 0 & 0 & 0 & 0 & $2(16.7)$ & $2(0.6)$ \\
\hline
\end{tabular}

If more than one $\mathrm{AE}$ was coded to the same preferred term for a patient, the patient was counted only once for that preferred term. For dysmenorrhea, percentages are relative to the number of female patients.

${ }^{\mathrm{a}} \mathrm{AEs}$ reported in descending order for RCT vilazodone treatment group.

${ }^{\mathrm{b}}$ Presyncope in the RCT and syncope in the OLE.

$\mathrm{AE}$, adverse event; TEAE, treatment-emergent adverse event; SAE, serious adverse event; ADO, adverse event leading to study discontinuation; URI, upper respiratory infection; PBO, placebo; VLZ, vilazodone; FLX, fluoxetine; $N$, number of patients in the Safety Population; $n$, number of patients who had the event.

Fredericia $>500$ msec or a clinically significant EKG finding during the RCT or OLE.

Mean changes in body weight from baseline to the end of the RCT were similar for placebo (0.80 [SD 1.7] $\mathrm{kg})$ and vilazodone $(0.92$ [SD 1.8] kg) and higher than fluoxetine $(0.08$ [SD 2.3] kg) patients. A similar number of patients in each treatment group $(6 \%$ placebo, $5.9 \%$ vilazodone, and $5.2 \%$ fluoxetine) had $\geq 7 \%$ increase in weight. Over 28 weeks in the OLE study, this increased to $\sim 45 \%$, but the analyses does not account for normal growth in children and adolescents. After accounting for growth by age and gender, in a combined analysis of the RCT and OLE, no patient experienced a change of $>2$ SDs from expected normal growth at the end of OLE, suggesting that, at least in part, the weight increase reflects age- and gender-appropriate development over this period. Less than $3 \%$ of patients in each treatment group in either the RCT or OLE had $\geq 7 \%$ decrease in weight.

\section{Discussion}

In this study, children and adolescents receiving flexibly-dosed vilazodone (15-30 mg/day), fluoxetine ( $20 \mathrm{mg} /$ day), and placebo experienced robust improvement in depressive symptoms. Vila- zodone was not significantly superior to placebo in primary or secondary efficacy measures in the 8-week RCT. Patients receiving fluoxetine were numerically more improved compared to those receiving vilazodone and placebo, but these improvements failed to reach statistical significance for the primary or secondary endpoint. The magnitude of improvement for fluoxetine was similar to that observed in the positive efficacy study that led to U.S. FDA approval for fluoxetine [changes from baseline of -22.71 (RCT) and -22.0 points (Emslie et al. 2002) on the CDRS-R]; however, in both RCTs of vilazodone the improvements in the placebo group [change from baseline of -20.32 (Durgam et al. 2018) and -22.48, respectively] were much greater than seen in the fluoxetine registration study (change from baseline of -14.9 points for placebo). Thus, the large placebo-related improvements in the CDRS-R score likely degraded our ability to detect treatment differences between vilazodone and placebo. A standard definition of CDRS-R response is not available in the literature. The positive fluoxetine study (Emslie et al. 2002) prospectively defined a $30 \%$ or greater improvement in the CDRS-R score, but the difference in the percentage of patients responding to treatment was not statistically significant versus placebo. In the study by Emslie et al. (2002), fluoxetine response was assessed over a range of $\geq 20 \%$ to $\geq 70 \%$ 
reduction in CDRS-R score, and fluoxetine was significantly superior to placebo at the $\geq 40 \%$ improvement criteria, so this definition was prespecified for analysis in the current study. At this threshold vilazodone numerically improved response rates versus placebo $(51.3 \%$ vs. $43.2 \%)$, but the difference did not reach statistical significance.

Over the past several decades, increasing placebo response rates in clinical trials of SSRI and serotonin-norepinephrine reuptake inhibitors in pediatric patients with depressive and anxiety disorders have affected our ability to detect drug-placebo differences. Moreover, this challenge in child and adolescent psychiatry clinical trials compels us to better understand and predict placebo response in this patient population (Nakonezny et al. 2015; Dobson and Strawn 2016; Locher et al. 2017; Walkup 2017; Strawn et al. 2018). In this regard, meta-analyses have identified both methodological and patient-related factors that potentially increase placebo response in pediatric MDD trials (Cohen et al. 2008, 2010; Bridge et al. 2009; Nakonezny et al. 2015; Mills et al. 2019). These warrant additional discussion and provide context for the results of the current trial and have implications for future trial design.

Among the notable methodological factors, a high number of study sites, inclusion of study sites with low enrollment numbers, and number of participant visits (interactions with clinic staff) have all been associated as potential factors contributing to high placebo effect in depression studies (Bridge et al. 2009; Dobson and Strawn 2016). In one report, studies with many sites tended to recruit participants with less severe illness, suggesting that screening may be less stringent in trials with more sites (Bridge et al. 2009). While most of the features that characterize MDD in adults are similar in pediatric patients, there are key differences that can be overlooked or mistaken for "typical" adolescent behavior (Neavin et al. 2018). In addition, pediatric patients are less likely to have the emotional vocabulary, emotional insight, or expressive language to communicate their emotional states (Thapar et al. 2012). Furthermore, placebo effects in pediatric patients vary as a function of disorder; while response to antidepressants may be similar across diagnostic groups, response to placebo is higher among youths with MDD (50\%) compared to those with obsessive compulsive disorder (OCD) and non-OCD anxiety disorders (32\% and 39\%, respectively) (Cohen et al. 2010; Locher et al. 2017). The confluence of these factors in the present trial has important implications, particularly as stakeholder (e.g., industry, FDA, academia) involvement increases during the design of these trials. Thus, this (and prior negative) trials raise the possibility that we should reevaluate some components that are considered "regulatory essentials" and "standard" in RCTs. These factors include multiple doses (which increase placebo response through expectation), fixed randomization ratios, and enrollment-based incentive structures that may actually degrade our ability to detect medication efficacy. This is particularly relevant given that placebo response is the largest determinant of "medication efficacy" in these trials (Locher et al. 2017; Mills et al. 2019).

One notable attribute of successful adolescent MDD trials, including the fluoxetine study mentioned previously and the escitalopram study that led to approval for adolescent MDD, is the implementation of a "placebo run-in period" consisting of a singleblind, 1-week, placebo lead-in period (between week -1 and week 0 ) where initial placebo response was defined as $\geq 30 \%$ decrease in CDRS-R or a CGI-I score of 1 or 2 (Emslie et al. 2002, 2009; Wagner et al. 2004). Although a lack of placebo run-in period has not yet been highly correlated with high placebo response (Bridge et al. 2009), in the trials where it was implemented it did presum- ably provide investigators with the opportunity to surveil and discontinue participants who no longer met the inclusion/exclusion criteria (Emslie et al. 2002, 2009; Wagner et al. 2004). Later trials conducted by some of the same investigators, which did not include the placebo lead-in, were not successful due to high placebo response rates (Atkinson et al. 2014; Emslie et al. 2014). The value of a placebo lead-in approach may also benefit a more accurate screening diagnosis through multiple visits/screening assessments, therefore, representing a key checkpoint in trial implementation.

While this is the largest study of vilazodone in pediatric patients with MDD, several limitations warrant additional discussion. First, this RCT was only 8 weeks long, and the inclusion and exclusion criteria may affect its generalizability. Second, the RCT was not designed nor powered to identify individual predictors of improvement and certain subsets of patients may have been more or less responsive to one or both of the study medications.

Importantly, no new safety signals were observed, and vilazodone was generally well-tolerated. Common TEAEs were similar to those previously reported in adolescents (Durgam et al. 2018) and adult patients (Rickels et al. 2009; Khan et al. 2011; Robinson et al. 2011; Croft et al. 2014; Mathews et al. 2015). Gastrointestinal disorders, nervous system disorders, and insomnia were reported with greater frequency in vilazodone-treated patients in both studies and were mostly mild, with the exception of insomnia, which was moderate. During the RCT, the number of vilazodonetreated patients with suicidal ideation was $15(8.1 \%)$ compared to $25(13.7 \%)$ in patients receiving placebo, based on both C-SSRS and reported AEs. Twelve percent of all patients in the OLE experienced suicidal ideation. These incidences are lower than the $17.2 \%$ prevalence of suicidal ideations among U.S. adolescents, as per the 2017 Youth Behavioral Risk Surveillance survey (Kann et al. 2018). Because of the possible association between antidepressant use in children and adolescents (Hammad et al. 2006; Bridge et al. 2007), this finding may be of importance. However, it is also noteworthy that the association between suicidality and antidepressant use in pediatric populations may be disorder and medication specific (Dobson et al. 2019; Mills et al. 2019).

\section{Conclusions}

In this phase 3 , double-blind placebo-controlled study, vilazodone $15-30 \mathrm{mg} /$ day was not statistically superior to placebo for the treatment of MDD in children and adolescents. Patients receiving placebo and vilazodone did not differ on any efficacy measure, although patients receiving placebo, vilazodone, and fluoxetine had improvement in depressive symptoms over the course of the trial. These results highlight the need to better understand and to mitigate the effects of placebo response. Importantly, vilazodone (15$30 \mathrm{mg} /$ day) was generally safe and well-tolerated in children and adolescents with adverse effects similar to those observed in other trials of adolescent and adult patients.

\section{Clinical Significance}

Efficacy of flexibly-dosed vilazodone $15-30 \mathrm{mg}$ /day for the treatment of MDD in children and adolescents was not demonstrated in this 8-week, double-blind placebo-controlled study. No statistically significant difference from placebo on the primary efficacy endpoint (CDRS-R) or any secondary efficacy endpoint was observed for either vilazodone $(15-30 \mathrm{mg} /$ day $)$ or fluoxetine $(20 \mathrm{mg} /$ day $)$ treatment arms. Treatment with vilazodone $(15-30 \mathrm{mg} /$ day) was generally safe and well-tolerated in this study with no new safety signals observed. 


\section{Disclaimer}

Data reported in this article are available within the article (and/or) its Supplementary Data. Allergan (now AbbVie) will share deidentified patient-level data and/or study-level data, including protocols and clinical study reports, for Phase 2-4 trials completed after 2008 that are registered on ClinicalTrials.gov or EudraCT. The indication studied in the trial must have regulatory approval in the United States and/or the European Union, and the primary article from the trial must be published before data sharing. To request access to the data, the researcher must sign a data use agreement. All shared data are to be used for noncommercial purposes only. More information can be found on http://allerganclinicaltrials.com/

\section{Role of the Sponsors}

Allergan plc (now AbbVie) was involved in the study design, collection (through contracted clinical investigator sites), analysis and interpretation of data, and decision to present these results.

\section{Acknowledgments}

Writing assistance and editorial support in the preparation of this manuscript was provided by Cherisse Loucks, $\mathrm{PhD}$, and Erika von Grote, PhD, of AbbVie (Madison, New Jersey, USA). The authors acknowledge Jing Xia for her contributions to the analysis of these data. The authors also thank the patients and families who participated in these trials and the investigators and study staff at the individual sites.

\section{Disclosures}

Dr. J.R.S. has received research support from the National Institutes of Health (NIMH/NIEHS/NICHD), the Yung Family Foundation, as well as Allergan (now AbbVie), Otsuka, and Neuronetics. He has received material support from and provided consultation to Myriad Genetics. He receives royalties from the publication of two texts (Springer), serves as an author for UpToDate and an Associate Editor for Current Psychiatry, and has received honoraria from CMEology and Neuroscience Educational Institute. Dr. E.M. is a full-time employee of AbbVie. Dr. R.L.F. receives or has received research support, acted as a consultant, and/or has received honoraria from Acadia, Aevi, Akili, Alcobra, Allergan (now AbbVie), Alkermes, Amerex, American Academy of Child and Adolescent Psychiatry, American Psychiatric Press, Arbor, Axsome, Daiichi-Sankyo, Genentech, KemPharm, Luminopia, Lundbeck, MedAvante-ProPhase, Merck, National Institutes of Health, Neurim, Noven, Nuvelution, Otsuka, PCORI, Pfizer, Physicians Postgraduate Press, Purinix, Q BioMed, Receptor Life Sciences, Roche, Sage, Signant Health, Sunovion, Supernus Pharmaceuticals, Syneurx, Takeda, Teva, TouchPoint, and Validus.

\section{Supplementary Material}

Supplementary Figure S1

Supplementary Table S1

\section{References}

American Psychiatric Association: Diagnostic and Statistical Manual of Mental Disorders, 4th ed., Text Revision. Washington, DC: American Psychiatric Association; 2000.

Atkinson SD, Prakash A, Zhang Q, Pangallo BA, Bangs ME, Emslie GJ, March JS: A double-blind efficacy and safety study of duloxetine flexible dosing in children and adolescents with major depressive disorder. J Child Adolesc Psychopharmacol 24:180-189, 2014.
Bridge JA, Birmaher B, Iyengar S, Barbe RP, Brent DA: A placebo response in randomized controlled trials of antidepressants for pediatric major depressive disorder. Am J Psychiatry 166:42-49, 2009.

Bridge JA, Iyengar S, Salary CB, Barbe RP, Birmaher B, Pincus HA, Ren L, Brent DA: Clinical response and risk for reported suicidal ideation and suicide attempts in pediatric antidepressant treatment: A meta-analysis of randomized controlled trials. JAMA 297:1683-1696, 2007.

Cohen D, Consoli A, Bodeau N, Purper-Ouakil D, Deniau E, Guile JM, Donnelly C: Predictors of placebo response in randomized controlled trials of psychotropic drugs for children and adolescents with internalizing disorders. J Child Adolesc Psychopharmacol 20: 39-47, 2010.

Cohen D, Deniau E, Maturana A, Tanguy ML, Bodeau N, Labelle R, Breton JJ, Guile JM: Are child and adolescent responses to placebo higher in major depression than in anxiety disorders? A systematic review of placebo-controlled trials. PLoS One 3:e2632, 2008.

Croft HA, Pomara N, Gommoll C, Chen D, Nunez R, Mathews M: Efficacy and safety of vilazodone in major depressive disorder: A randomized, double-blind, placebo-controlled trial. J Clin Psychiatry 75:e1291-e1298, 2014.

Davies J, Sullivan S, Zammit S: Adverse life outcomes associated with adolescent psychotic experiences and depressive symptoms. Soc Psychiatry Psychiatr Epidemiol 53:497-507, 2018.

Dobson ET, Bloch MH, Strawn JR: Efficacy and tolerability of pharmacotherapy for pediatric anxiety disorders: A network metaanalysis. J Clin Psychiatry 80:17r12064, 2019.

Dobson ET, Strawn JR: Placebo response in pediatric anxiety disorders: Implications for clinical trial design and interpretation. J Child Adolesc Psychopharmacol 26:686-693, 2016.

Durgam S, Chen C, Migliore R, Prakash C, Edwards J, Findling RL: A phase 3, double-blind, randomized, placebo-controlled study of vilazodone in adolescents with major depressive disorder. Pediatr Drugs 20:353-363, 2018.

Emslie GJ, Heiligstein JH, Wagner KD, Hoog SL, Ernest DE, Brown E, Nilsson M, Jacobson JG: Fluoxetine for acute treatment of depression in children and adolescents: A placebo-controlled, randomized clinical trial. J Am Acad Child Adolesc Psychiatry 41: 1205-1215, 2002.

Emslie GJ, Kennard BD, Mayes TL, Nightingale-Teresi J, Carmody T, Hughes CW, Rush AJ, Tao R, Rintelmann JW: Fluoxetine versus placebo in preventing relapse of major depression in children and adolescents. Am J Psychiatry 165:459-467, 2008.

Emslie GJ, Mayes T, Porta G, Vitiello B, Clarke G, Wagner KD, Asarnow JR, Spirito A, Birmaher B, Ryan N, Kennard B, DeBar L, McCracken J, Strober M, Onorato M, Zelazny J, Keller M, Iyengar S, Brent D: Treatment of Resistant Depression in Adolescents (TORDIA): Week 24 outcomes. Am J Psychiatry 167:782-791, 2010.

Emslie GJ, Prakash A, Zhang Q, Pangallo BA, Bangs ME, March JS: A double-blind efficacy and safety study of duloxetine fixed doses in children and adolescents with major depressive disorder. J Child Adolesc Psychopharmacol 24:170-179, 2014.

Emslie GJ, Ventura D, Korotzer A, Tourkodimitris S: Escitalopram in the treatment of adolescent depression: A randomized placebocontrolled multisite trial. J Am Acad Child Adolesc Psychiatry 48: 721-729, 2009.

Foley DL, Goldston, DB, Costello J, Angold A: Proximal psychiatric risk factors for suicidality in youth: The great smoky mountains study. Arch Gen Psychiatry 63:1017-1024, 2006.

Guy W: Clinical global impressions scale. In: ECDEU Assessment Manual for Psychopharmacology-Revised. Rockville, MD, US Department of Health, Education, and Welfare, Public Health Service, Alcohol, Drug Abuse, and Mental Health Administration, National Institute of Mental Health, Psychopharmacology Research Branch, Division of Extramural Research Programs, 1976, pp. 217-222. 
Hammad TA, Laughren T, Racoosin J: Suicidality in pediatric patients treated with antidepressant drugs. Arch Gen Psychiatry 63: 332-339, 2006.

Kann L, McManus T, Harris WA, Shanklin SL, Flint KH, Queen B, Lowry R, Chyen D, Whittle L, Thornton J, Lim C, Bradford D, Yamakawa Y, Leon M, Brener N, Ethier KA: Youth risk behavior surveillance-United States, 2017. MMWR Surveill Summ 67:1114, 2018.

Kaufman J, Birmaher B, Brent D, Rao U, Flynn C, Moreci P, Williamson D, Ryan N: Schedule for affective disorders and schizophrenia for school-age children-present and lifetime version (KSADS-PL): Initial reliability and validity data. J Am Acad Child Adolesc Psychiatry 36:980-988, 1997.

Kenward M, Roger J: Small sample inference for fixed effects from restricted maximum likelihood. Biometrics 53:983-997, 1997.

Kessler RC, Petukhova M, Sampson NA, Zaslavsky AM, Wittchen HU: Twelve-month and lifetime prevalence and lifetime morbid risk of anxiety and mood disorders in the United States. Int J Methods Psychiatr Res 21:169-184, 2012.

Khan A, Cutler AJ, Kajdasz DK, Gallipoli S, Athanasiou M, Robinson DS, Whalen H, Reed CR: A randomized, double-blind, placebocontrolled, 8-week study of vilazodone, a serotonergic agent for the treatment of major depressive disorder. J Clin Psychiatry 72:441-447, 2011.

Locher C, Koechlin H, Zion SR, Werner C, Pine DS, Kirsch I, Kessler $\mathrm{RC}$, Kossowsky JEfficacy and safety of selective serotonin reuptake inhibitors, serotonin-norepinephrine reuptake inhibitors, and placebo for common psychiatric disorders among children and adolescents: A systematic review and meta-analysis. JAMA Psychiatry 74:1011-1020, 2017.

Lu K: Sample size calculations with multiplicity adjustment for longitudinal clinical trials with missing data. Stat Med 31:19-28, 2012.

Mathews M, Gommoll C, Chen D, Nunez R, Khan A: Efficacy and safety of vilazodone 20 and $40 \mathrm{mg}$ in major depressive disorder: A randomized, double-blind, placebo-controlled trial. Int Clin Psychopharmacol 30:67-74, 2015.

Merikangas KR, Ames M, Cui L, Stang PE, Ustun B, von Korff M, Kessler RC: The impact of comorbidity of mental and physical conditions on role disability in the US adult household population. Arch Gen Psychiatry 64:1180-1188, 2007.

Mills JA, Mossman SA, Strawn JR: The impact of funding source on antidepressant trial outcomes in pediatric depressive and anxiety disorders. J Am Acad Child Adolesc Psychiatry 58:S253, 2019.

Mufson L, Dorta KP, Wickramaratne P, Nomura Y, Olfson M, Weissman MM: A randomized effectiveness trial of interpersonal psychotherapy for depressed adolescents. Arch Gen Psychiatry 61:577-584, 2004.

Mufson L, Weissman MM, Moreau D, Garfinkel R: Efficacy of interpersonal psychotherapy for depressed adolescents. Arch Gen Psychiatry 56:573-579, 1999.

Nakonezny PA, Mayes TL, Byerly MJ, Emslie GJ: Predicting placebo response in adolescents with major depressive disorder: The Adolescent Placebo Impact Composite Score (APICS). J Psychiatr Res 68:346-353, 2015.

Neavin DR, Joyce J, Swintak C: Treatment of major depressive disorder in pediatric populations. Diseases 6:pii: E48, 2018.

Posner K, Brown GK, Stanley B, Brent DA, Yershova KV, Oquendo MA, Currier GW, Melvin GA, Greenhill L, Shen S, Mann JJ: The Columbia-Suicide Severity Rating Scale: Initial validity and internal consistency findings from three multisite studies with adolescents and adults. Am J Psychiatry 168:1266-1277, 2011.

Poznanski EO, Mokros HB: Children's Depression Rating Scale Revised (CDRS R). Los Angeles (California), Western Psychological Services, 1996.
PROZAC $^{\circledR}$. [Fluoxetine hydrochloride]: Eli Lilly and Company. 2014. Available at https://accessdata.fda.gov/drugsatfda_docs/ label/2011/018936s091lbl.pdf (Accessed March 23, 2020).

Rickels K, Athanasiou M, Robinson DS, Gibertini M, Whalen H, Reed CR: Evidence for efficacy and tolerability of vilazodone in the treatment of major depressive disorder: A randomized, doubleblind, placebo-controlled trial. J Clin Psychiatry 70:326-333, 2009.

Robinson DS, Kajdasz DK, Gallipoli S, Whalen H, Wamil A, Reed CR: A 1-year, open-label study assessing the safety and tolerability of vilazodone in patients with major depressive disorder. J Clin Psychopharmacol 31:643-646, 2011.

Strawn JR, Croarkin PE: Desvenlafaxine versus placebo in a fluoxetine-referenced study of children and adolescents with major depressive disorder: Design, definitions, and ongoing challenges for child and adolescent psychopharmacology research. J Child Adolesc Psychopharmacol 28:363, 2018.

Strawn JR, Dobson ET, Giles LL: Primary pediatric care psychopharmacology: Focus on medications for ADHD, depression, and anxiety. Curr Probl Pediatr Adolesc Health Care 47:3-14, 2017.

Temple R: Hy's law: Predicting serious hepatotoxicity. Pharmacoepidemiol Drug Saf 15:241-243, 2006.

Thapar A, Collishaw S, Pine DS, Thapar AK: Depression in adolescence. Lancet 379:1056-1067, 2012.

The Treatment for Adolescents with Depression Study (TADS) Team, March J, Silva S, Curry J, Wells K, Fairbank J, Burns B, Domino M, Vitiello B, Severe J, Riedal K, Goldman M, Feeny N, Findling R, Stull S, Baab S, Weller EB, Robbins M, Weller RA, Jessani N, Waslick B, Sweeney M, Dublin R, Walkup J, Ginsburg G, Kastelic E, Koo H, Kratochvil C, May D, LaGrone R, Vaughan B, Albano AM, Hirsch GS, Podniesinki E, Chu A, Reincecke M, Leventhal B, Rogers G, Jacobs R, Pathak S, Wells J, Lavanier SA, Danielyan A, Rohde P, Simons A, Grimm J, Frank S, Emslie G, Kennard B, Hughes C, Mayes TL, Rosenberg D, Benazon N, Butkus M, Bartoi M: The treatment for adolescents with depression study (TADS): Outcomes over 1 year of naturalistic follow-up. Am J Psychiatry 166:1141-1149, 2009.

Wagner KD, Ambrosini P, Rynn M, Wohlberg C, Yang R, Greenbaum MS, Childress A, Donnelly C, Deas D: Efficacy of sertraline in the treatment of children and adolescents with major depressive disorder: Two randomized controlled trials. JAMA 290:1033-1041, 2003.

Wagner KD, Robb AS, Findling RL, Jin J, Gutierrez MM, Heydorn WE: A randomized, placebo-controlled trial of citalopram for the treatment of major depression in children and adolescents. Am J Psychiatry 161:1079-1083, 2004.

Walkup JT: Antidepressant efficacy for depression in children and adolescents: Industry- and NIMH-funded studies. Am J Psychiatry 174:430-437, 2017.

World Health Organization: Adolescent Health Epidemiology. Available at: http://who.int/maternal_child_adolescent/epidemiology/ adolescence/en/ (Accessed June 20, 2019).

Viibryd $^{\circledR}$. [Vilazodone HCl]: Allergan plc. 2017. Available at: http:// allergan.com/assets/pdf/viibryd_pi (Accessed March 27, 2019).

Address correspondence to: Robert L. Findling, MD, MBA

Department of Psychiatry

Virginia Commonwealth University 501 North 2nd Street, Suite 400

Box 980308

Richmond, VA 23298-0308

USA

E-mail: robert.findling@vcuhealth.org 